\title{
EXPERIMENTS IN THE CONTROL OF DAMPING-OFF AT THE NURSERY, ORONO, ONTARIO ${ }^{1}$ BY J. COCKERILL ${ }^{2}$
}

John Cockerill graduated from the University of Toronto with the degree of B.SC.F. in 1950. He joined the staff of the Forest Pathology Laboratory, Maple, Ontario, in 1950 and has since been working on the nursery disease investigation program of the Laboratory.

\section{ABSTRACT}

Soil acidification treatments using ferrous sulphate and sawdust mulch were not effective in controlling damping-off losses in forest nursery seed beds at Orono, Ontario. Soil fumigation with methyl-bromide resulted in reduced pre-emergence losses and consequent higher emergences of seedlings. This treatment, however, failed to provide adequate protection during a period of severe damping-off. Total mortality in fumigated beds was comparable to that recorded in untreated beds. The failure of methyl-bromide to provide continued protection during the period of severe damping-off limits its use as a control treatment.

\section{INTRODUCTION}

Previous investigations of damping-off at the Orono Nursery, in which soil amendments and fertilization treatments were used, revealed that a mulch of peat was an effective treatment for reducing damping-off losses. However, the expense of treating a large area, and the lack of a suitable mechanical applicator for spreading the peat, made it desirable to find other treatments which, while providing a satisfactory control, would be less expensive and easier to apply.

The effectiveness of peat had been shown to be due partly to its acidity and partly to other properties, pessibly of a biological or mechanical nature (1). Treatments, using a sawdust mulch and soil acidification, were suggested for further study. In addition to these a soil fumigation treatment using methylbromide $^{3}$ was used. This fumigant, when used as a weed eradicator, had shown promise for the control of damping-off and a further examination of its control capabilities was desirable.

\section{Procedure}

An experiment undertaken in 1953 was designed to test the degree of control of damping-off obtained through the use of the following treatments: 1) a sawdust mulch of mixed conifer and hardwood sawdust, approximately 1 inch thick;

2) an application of ferrous sulphate ${ }^{4}$ at the rate of $4.13 \mathrm{lb}$,, per 120 square feet;

${ }^{1}$ Manuscript received October 30, 1956. Contribution No. 340 from the Forest Biology Division, Science Service, Department of Agriculture, Ottawa, Canada.

${ }^{2}$ Forest Pathology Laboratory, Southern Research Station, Maple, Ontario.

Dowfume $\mathrm{MC}_{2}$-Dow Chemical Co.

- as Copperas-commercial grade of ferrous sulphate. 
3) a fall fumigation using methyl-bromide at the rate of $4 \mathrm{lb}$., per 120 square feet;

4) a spring fumigation of methyl-bromide at the rate of $4 \mathrm{lb}$., per 120 square feet.

The spring fumigation was considered necessary as a check on the persistence of the fall fumigation during the over-winter period.

Since methyl-bromide is injurious to seed, the seed beds receiving this treatment were left for two days after fumigation to allow the gas to dissipate before the seed was sown.

Each treatment was applied to one-half of a standard seed bed, an area of approximately $60 \mathrm{sq}$. $\mathrm{ft}$. The five treatments were randomized in twelve replications. To obtain a record of seedling mortality, injury, and survival frequent examinations were made of sample areas established in each plot.

Examination of the fall-sown beds began on May 29 when seedling emergence was well advanced. In the spring-treated beds sowing had been delayed and these were not examined until June 23.

\section{Analysis of the Data}

The later germination and emergence in the spring-sown treatments exposed the seedlings to temperature and moisture conditions which were not comparable to those prevailing during the early growth period of the seedlings in the fall-sown beds. The spring beds also suffered heavily from the activity of birds, which removed the seed coat from the seedlings just prior to the elongation of the cotyledons. Because of the differences in growing conditions and the heavy damage, the data for the spring-sown beds were not included in the statistical analysis. They are entered for record purposes in Tables I and II.

In addition to comparing the effectiveness of the various treatments, the analysis of the data was made in a manner to show the relationship between seedling age and susceptibility to damping-off. To do this the data were grouped by periods of approximately one week. In all treatments the mortality had dropped to a low level by the end of the fourth week, and, as no additional information could be gained by using the data beyond this point, the analysis deals only with the data of the first four weeks.

Summaries of the emergence, mortality, and survival data are presented in Tables I and II.

From the analysis of variance and covariance, the following conclusions could be made:

1) the treatments had no significant effect on the absolute amount of mortality;

2) there was a significant difference in the mortality from week to week;

3) the pattern of weekly decrease in mortality between treatments was significant;

4) the difference in mortality between replications was significant.

A further analysis of variance and covariance was made with respect to the survival at the beginning of each week. This analysis showed that:

1) there were significant differences in survival between treatments;

2 ) the decrease in mortality was not due solely to the reduced number of seedlings in the beds. 
TABLE I

Total Number of Live Seedlings at the Start of Each Week and Total Mortality During the Week, For the Twelve Replications

\begin{tabular}{|c|c|c|c|c|c|c|c|c|}
\hline \multirow[b]{2}{*}{ Treatment } & \multicolumn{6}{|c|}{ Week } & \multirow[b]{2}{*}{7} & \multirow[b]{2}{*}{8} \\
\hline & 1 & 2 & 3 & 4 & 5 & 6 & & \\
\hline \multicolumn{9}{|l|}{1 Sawdust } \\
\hline live see & 5078 & 3671 & 2630 & 2343 & 2304 & 283 & 273 & 2260 \\
\hline mortal & 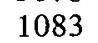 & 99 & 264 & 32 & 21 & 8 & 11 & \\
\hline \multicolumn{9}{|l|}{2 Ferrous sulphate } \\
\hline live seedlings & 5114 & 3265 & 2379 & 2055 & 1946 & 1910 & 1890 & 1882 \\
\hline mortal & 1435 & 853 & 304 & 101 & 35 & 15 & 8 & \\
\hline \multicolumn{9}{|l|}{3 Dowfume (fall) } \\
\hline live seedlings & 7100 & 5535 & 4738 & 4269 & 4027 & 3955 & 3894 & 3865 \\
\hline mort & 1 & 76 & 453 & 215 & 64 & 55 & 25 & \\
\hline \multicolumn{9}{|l|}{4 Dowfume (spring) } \\
\hline live seedlings & & & & 7578 & 6357 & 4257 & 3107 & 2407 \\
\hline mortalit & & & & 79 & 1280 & 845 & 584 & \\
\hline \multicolumn{9}{|l|}{5 Control } \\
\hline live & 508 & 3275 & 2481 & 2189 & 2055 & 2008 & 1986 & 1980 \\
\hline mortality & 1537 & 764 & 282 & 129 & 42 & 18 & 5 & \\
\hline
\end{tabular}

TABLE II

Summary of Seedling Emergence, Mortality, Survival, and Damage FOR THE FIVE SOIL TREATMENTS

\begin{tabular}{lcccc}
\hline Treatment & $\begin{array}{c}\text { Emergence } \\
\text { No. }\end{array}$ & $\begin{array}{c}\text { Mortality } \\
\text { No. }\end{array}$ & $\begin{array}{c}\text { Damage } \\
\text { No. }\end{array}$ & $\begin{array}{c}\text { Survival } \\
\text { No. }\end{array}$ \\
\hline 1 Sawdust & 5078 & 2414 & 404 & 2260 \\
2 Ferrous sulphate & 5114 & 2749 & 483 & 1882 \\
3 Dowfume (fall) & 7100 & 2726 & 509 & 3865 \\
4 Dowfume (spring) & 7578 & 2788 & 2383 & 2407 \\
5 Control & 5089 & 2777 & 332 & 1980 \\
\hline
\end{tabular}

\section{Discussion}

Since the analysis showed a sigaificant difference in seedling survival between treatments, but no difference in the absolute mortality, the difference in survival must have resulted from a higher seedling emergence in one or more of the treatments. The field data for the fall sown beds shows that this was so in the methyl-bromide treatments. This higher emergence resulting, no doubt, from a reduction in pre-emergence losses in these beds, indicates that the fumigation was effective in controlling damping-off. However, the high mortality in these beds, which was similar to that in the untreated beds, indicates that the initial control of the methyl-bromide did not continue to be effective into the growing season, probably owing to a build-up in the numbers of pathogenic fungi in the treated beds.

A similar effect was observed in the spring-treated beds. In these beds the effectiveness of the methyl-bromide in the initial stages was again evident in low mortalities recorded during the first week. Soon, however, the mortality 
rate increased notably, indicating that an increased activity of the damping-off fungi occurred as the effect of the methyl-bromide diminished.

The failure of methyl-bromide to provide protection during the early growth period, when the seedlings are most susceptible to damping-off, makes its use of questionable value in the nursery.

The other treatments had little or no control over damping-off. The sawdust mulch produced slightly better results than observed in the check area and the acidification treatment produced no appreciable control. The results obtained with these treatments would not justify their use as controls for damping-off at the Orono Nursery.

The reduction in mortality, which was shown by the analysis to be due to more than a reduction in the number of seedlings which could be attacked, may have resulted from a decrease in the activity of the pathogenic fungi or from an increase in resistance to damping-off in the older seedlings. The high mortality recorded in the spring-sown beds suggests that there was little reduction in the activity of the fungi during this period. It is likely, therefore, that the reduction in mortality which occurred in the latter part of the experiment was due to an increased resistance of the older seedlings to fungal attack.

\section{Conclusions}

The sawdust mulch and soil acidification treatments were not effective in controlling damping-off under the conditions encountered in this experiment.

Fumigating the soil with methyl-bromide produced a denser stand of seedlings, without a proportional increase in mortality, through a reduction in pre-emergence losses. The effectiveness of the methyl-bromide treatment would permit sowing at a lower density in the seed beds if the protection continued into the spring growing season. However, the failure of the treatment to remain effective over the winter period leaves the seed bed open to reinfection in the spring, when protection is needed most. This lack of protection could result in excessive losses during a period of severe damping-off and, if the rate of sowing had been reduced on the basis of an expected increase in emergence, the loss in seedling production would defeat the purpose of the treatment. For this reason the treatment should be used with caution as a control for damping-off.

\section{ACKNOWLEDGMENTS}

The author wishes to express his appreciation to Dr. L. T. White, Officerin-Charge of the Forest Pathology Laboratory, Maple, for his continued interest and helpful advice and criticism throughout the investigation.

He is especially grateful to Dr. T. T. Schwitzer, formerly of the Ontario Research Foundation, for undertaking the task of preparing the statistical analysis and to Dr. D. B. De Lury of the Ontario Research Foundation for his advice on the design of the experiment.

Thanks are due to Mr. G. M. Linton, Superintendent of the Orono Nursery, for providing facilities for carrying out the investigation.

\section{REFERENCES}

1. COCKERILL, J. Studies in damping-off, Orono, 1952. Interim Report, Forest Pathology Laboratory, Maple, Ontario. 